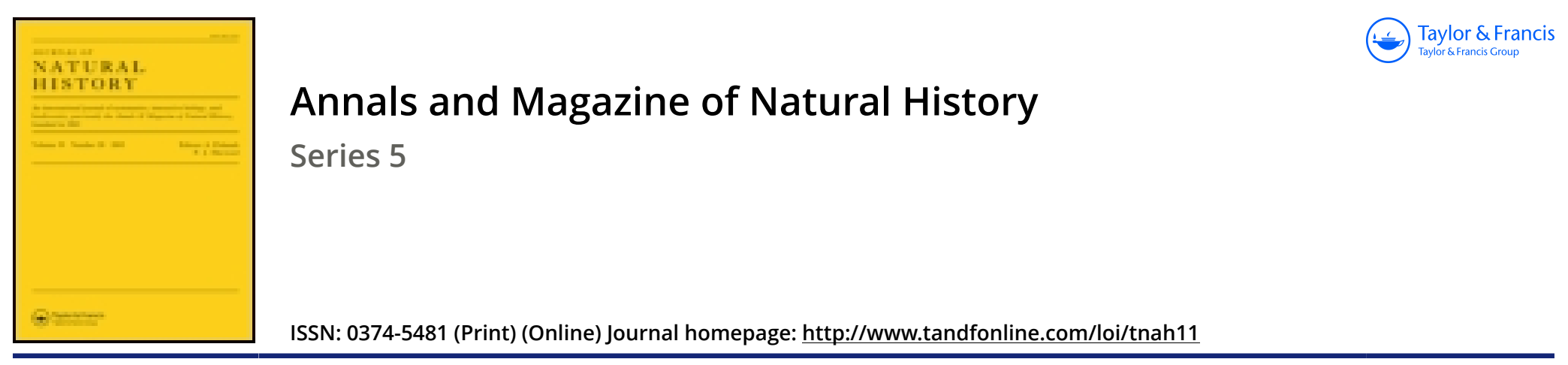

\title{
VIII.--Notes on Indian land and freshwater mollusks.-No. I. On the discrimination of the sexes in the genus Paludina
}

\section{J. Wood-Mason}

To cite this article: J. Wood-Mason (1881) VIII.-Notes on Indian land and freshwater mollusks.-No. I. On the discrimination of the sexes in the genus Paludina, Annals and Magazine of Natural History, 8:44, 85-88, DOI: 10.1080/00222938109487419

To link to this article: http://dx.doi.org/10.1080/00222938109487419

曲 Published online: 09 Oct 2009.

Submit your article to this journal $\pi$

Џll Article views: 3

Q View related articles $\triangle$

Citing articles: 1 View citing articles 


\section{EXPLANATION OF PLATE $X$.}

The numbers placed beside the figures express the enlargement in diameters.

Fig. 1. A nymph of Tricoryphus (sp. ?), $\times 5, a$, rudimentary respiratory organ of the first segment; the chitinous plate, $b$, has been removed on one side to show the following respiratory organs.

Fig. 2. Batisca obesa, seen from above and drawn from a nymphal envelope, in which the last segment and the antennæ were deficient, $\times 5$.

Fig. 3. Prosopistoma punctifrons, nymphal stage, seen from above, $\times 12$. The left half of the carapace has been removed to show, in front, the digestive tube partly concealed by the left lobe of the genital gland; behind, the interior of the respiratory chamber, in which is the sheath of the lower wing $(f)$ concealing the points of insertion of the first two tracheo-branchio.

Fig. 4. Prosopistoma punetifrons, nymphal stage, seen from below, $\times 12$. The last segment, with the setre, has withdrawn into the ninth segment; at $v$ and $v^{\prime}$ are the apertures which give the water access to the respiratory chamber.

Fig. 5. One of the ova found in the body of the subimago of Prosopistoma, $\times 120$.

Fig. 6. One of the nodosities of this ovum, much enlarged, $\times 400$.

Fig. 7. Female (subimago) of Prosopistoma punctifrons, seen from above, $\times 14$. The stigmatic apertures may be seen on the right side of the third, fourth, fifth, and sixth segments.

Fig. 8. The same, seen from below, $\times 14$. In order to avoid making this figure too complicated, I have not represented the legs of the second and third pairs, and I have left only the first two joints of those of the first pair.

Fig. 9. Base of the jnner surface of an upper wing, $\times 30$.

Fig. 10. Fragment of the posterior margin of the same wing, to show the multitude of hairs which cover both surfaces of the organs of flight, $\times 30$.

Fig. 11. Lower wing, $\times 18$.

Fig. 12. Right compound eye and lateral ocellus, in their respective position, $\times 30.12 a$ is a hair from the integument of this region, much enlarged.

Fig. 13. Antennæ, $\times 60$.

Fig. 14. Leg of the third pair, $\times 50$.

Fig. 15. Ventral surface of the abdomen of the female subimago, $\times 85$.

Fig. 16. One of the two plates forming the ventral surface of the last segment, $\times 80$.

Fig. 17. The three setæ of Prosopistoma in the perfect state, $\times 80$.

N.B. In several of the figures I have not represented the villosity due to the presence of the hairs which cover the integuments and the wings of the subimago.

VIII.-Notes on Indian Land and Freshwater Mollusks.No. I. On the Discrimination of the Sexes in the Genus Paludina. By J. Wood-Mason, Deputy Superintendent, Indian Museum, Calcutta, on Special Duty in Assam.

WHile at Balaganj and Panchuganj, on the Kusiara river, in Central Sylhet, on my way to Cachar, I was struck by the 
marked difference in size presented by the shells of a species of Paludina which lay in thousands at the bottom of the broad and shallow ditches close to the river-bank: shells of two distinct sizes, a larger and a smaller (not, so far as I could see, graduating into one another), were observed. This difference of size evidently not depending upon age, but being probably sexual, I determined to investigate the matter as soon as opportunity offered.

On my arrival at Silchar my native collector brought me, amongst other freshwater mollusks, five specimens of a Paludina* belonging to a totally distinct species from the one observed at Balaganj and Panchuganj. Of these, three of the same size were smaller and rather less ventricose than the other two, which also agreed with one another in size. In order to ascertain whether any difference in the external form of the animals accompanied the obvious difference between their shells in point of size, I placed the specimens in a plate of water. In a few minutes the mollusks emerged from their shells; and I at once noticed that, while the acuminate tentacles of the two larger ones were both quite straight, the right tentacle in each of the three smaller ones was strongly bent outwards and inwards upon itself, or hooked and somewhat swollen, and rather more darkly pigmented than its fellow of the opposite side or than the tentacles of the larger ones-an observation which suggested the suspicion that in the former case one had to do with males, and in the latter with females.

To place the matter beyond all doubt, I dissected two of the smaller and one of the larger specimens; and I found in the genital gland and duct of the former two forms of spermatozoa in all stages of development, and in the uterus of the latter ova containing fully-formed embryo Gasteropods with foot, operculum, spirally-lined soft nautiloid shell, upturned proboscis, and all complete.

Considering it desirable that this observation should be verified by the examination of a larger series of examples, $I$ sent the collector to the river for a fresh supply; and he soon returned with seventy-six specimens. These were placed in a basin of water and sorted, like those previously obtained, into two sets, according to the form of the right tentacle; each set was then carefully gone over to sce that the sorting had been correctly carried out; and finally the sex of several individuals out of each set was determined by dissection and microscopic examination, with the result of completely con-

* I am indebted to my friend and colleague Mr. Geoffrey Nevill, C.M.Z.S., for the information that the name of this species is $P$. crassa, Hutton. 
firming the conclusion already arrived at, namely that males can, in this species of Paludina, be distinguished from females by their smaller and less ventricose shells and by their right tentacle being hooked.

Of the seventy-six specimens thirty proved to be males, and forty-six females; the latter sex thus greatly predominated in the series collected; but whether this predominance would be maintained in a much more extensive series is to be doubted, especially as the tendency of most collectors of zoological specimens is to take the fine and to leave the small and juvenile individuals of a species. In each set there occurred only a single aged individual, with the apex of the shell much eroded. Of the forty shells classed as females a few young ones, with the peristome still thin and fragile, and in size equal to and less than males of average proportions, cannot be distinguished from these, and may possibly be immature males which have not yet acquired the hook to the tentacle; but all the rest can readily be distinguished from those classed as males. It is to be expected that individuals of one sex partaking of the characters of the other will occasionally occur, just as in the human species feminine men and masculine women, and in crustacea female crabs with male tails, are met with; and in such cases it may be difficult, if not impossible, for a conchologist to decide upon the evidence of the shell alone to which sex a specimen belongs.

The knowledge of this fact in the natural history of Paludina may prove useful to conchologists engaged in working out the fiuna of regions or of rocks, such as the Intertrappean beds of the Deccan, in which the genns abounds; but it is far from probable that any other Gasteropodous genera will be found to present similar sexual differences, the large and swollen shell of females in Paludina being in obvious correlation with the viviparous habits universal in the genus but unknown in other Gasteropoda, being, in fact, necessitated by the great bulk gradually attained by the uterus as the eggs develop within it into hard-shelled young Paludince.

In the European Paledina vivipara a distinct penis is present, and, according to Owen*, " is closely connected with the right tentacle;" but in the Indian species the penis is altogether aborted, and its function has been transferred to the contiguous right tentacle, which has consequently become converted into a hooked copulatory organ. Analogous to this is the case of the Dibranchiate Cephalopoda, in which one or other of the arms, according to the genus, functions as a penis

* 'Lectures on the Comparative Anatomy and Physiology of the Invertebrate Animals,' 2nd ed. 1855, p. 564. 
and is more or less considerably modified in form. And a more remote analogy is offered by male spiders, in which the tips of the pedipalps are curiously modified and perform the duty of conveying spermatophores to the genital aperture of the female.

My collector has since brought me, from a marsh in the immediate vicinity of the station, specimens of P. bengalensis, or a species closely allied thereto, in which also the right tentacle is hooked in the male.

Fig. 1.

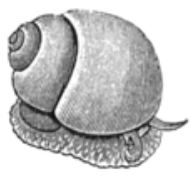

Fig. 4.

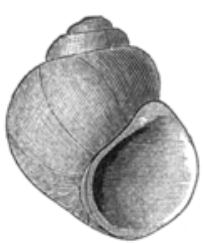

Fig. 2.

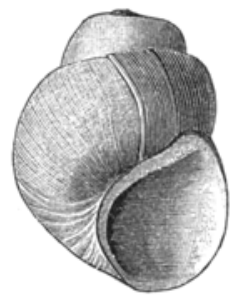

Fig. 3.

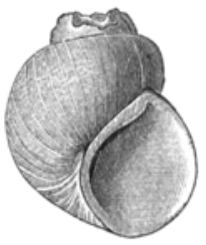

Fig. 5.

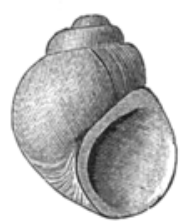

Fig. 1. View of a male $P$. crassa, to show the hooked right tentacle. Fig. 2. Shell of an aged female of $P$. crassit.

Fig. 3. Shell of an aged male.

Fig. 4. Shell of a female in the prime of life.

Fig. 5. Shell of a male in the prime of life.

Obs. The animals of the two aged specimens have prolonged their body-whorl much beyond the old peristome, corresponding to that of the two in the prime of life.

Silchar, Cachar, April 2, 1881.

IX.-Description of a new Volute from the South Coast of Australia. By Frederick M'Coy, F.R.S., Professor of Natural Science, University of Melbourne.

[Plate VII.]

Voluta Roadnightce (M'Coy).

(Pl. VII. figs. $1 \& 2$.)

Descr. Broad fusiform; pullus at apex of spire very large, smooth, spheroidal, oblique, of about $1_{\frac{1}{3}}$ turn; spire conical, 